\title{
Área superficial específica e capacidade de troca catiônica como parâmetros para avaliar e prever o consumo de defloculante $e$ viscosidade de barbotina
}

\author{
D. G. G. Delavi ${ }^{1}$, A. De Noni Jr ${ }^{1}$, D. Hotza ${ }^{1}$ \\ 1. Universidade Federal de Santa Catarina, Florianópolis, SC, Brazil. \\ e-mail: agenordenoni@gmail.com
}

\begin{abstract}
Resumo
Este trabalho mostra o estudo da defloculação de três argilas cauliníticas e duas argilas ilíticas, em suspenções aquosas, utilizando como defloculante silicatos e poliacrilatos a base $\mathrm{de}^{\mathrm{Li}^{+}}, \mathrm{Na}^{+}$e $\mathrm{K}^{+}$. Essas argilas foram caracterizadas e preparadas suspensões com $50 \%$ de sólidos. Curvas de defloculação foram determinadas em função da viscosidade e do tempo de escoamento. Com base no consumo de defloculante e com os resultados das caracterizações das argilas concluiu-se que as propriedades relacionadas com a natureza e quantidade da fase mineralógica presente nas matérias-primas afetam o consumo de defloculante e que a viscosidade é dependente da área de superfície específica (BET) da argila e não é função do consumo de defloculante.
\end{abstract}

Palavras-chave: Defloculação. Propriedades mineralógicas. Suspensões Aquosas de Argila.

\section{Introdução}

Uma parte significativa da produção de revestimentos cerâmicos adota o processo via úmida como rota para a preparação de massa. Produtos como porcelanato e monoporosa são preferivelmente produzidos dessa forma. A otimização desta etapa do processo passa por obter barbotinas com elevado conteúdo de sólidos e baixa viscosidade $^{[2,3,4]}$. Com essas características é possível reduzir o gasto energético nas etapas de moagem e secagem ${ }^{[2]}$. Os defloculantes são tradicionalmente empregados com esta finalidade e são auxiliares químicos que contribuem para a redução dos custos envolvidos na produção ${ }^{[2,3,3,6,67,8]}$.

Em meio líquido os pós cerâmicos apresentam tendência natural à aglomeração devido a atuação de forças de van der Waals ${ }^{[5,6,9]}$. Os aglomerados formados aprisionam água em seu interior tornando-se mais pesados, o resultado macroscópico corresponde a um aumento da viscosidade da suspensão ${ }^{[5,9]}$. Os defloculantes alteram a natureza das cargas superficiais resultantes das partículas, provocando repulsão entre elas. Em outras palavras, estes aditivos alteram o potencial eletrostático, denominado como potencial zeta, existente entre a camada compacta e camada difusa que se forma quando uma partícula de material sólido está dispersa em uma solução. Quanto maiores as cargas repulsivas, menor a viscosidade da barbotina.

Os argilominerais são as fases que mais interferem no comportamento reológico de uma barbotina. Possuem dimensões coloidais e são mais susceptíveis a foculação. O maior ou menor consumo de defloculante está diretamente associado a quantidade e tipo de fases argilominerais presentes em uma massa. A equação 1 é uma representação da interação, a nível iônico, que ocorre entre as partículas de uma fase argilominieral e um defloculante do tipo silicato de sódio. Os cátions monovalentes oriundos do silicato de sódio, solubilizados no meio aquoso, ocupam o lugar dos cátios divalentes, cálcio ou magnésio, presente na superfície das partículas. Como resultado gera-se um desequilíbrio de cargas eletrostáticas na superfície, passando de neutra para negativa, causando repulsão entre as partículas. Este sistema de troca catiônica não é irreversível, trata-se de um sistema reversível. Isso significa que o deslocamento do ponto de equilíbrio depende da concentração de cátios divalentes presente na solução aquosa. Em outras palavras, quanto maior a dureza da solução aquosa maior terá que ser o consumo de defloculante para deslocar o equilíbrio para uma condição ótima de trabalho. A parte aniônica de alguns defloculantes sequestram os cátions bivalentes do meio e os precipitam, favorecendo ainda mais a defloculação do sistema ${ }^{[12]}$. Porém com excesso de defloculante, excesso de cátions monovalentes, a carga da partícula é novamente anulada havendo um aumento de viscosidade, como mostrado na reação de troca catiônica ${ }^{[5,13]}$.

$$
\begin{aligned}
& {\left[\left(\text { Argila.Ca }^{2+}\right)^{0}+\left(\mathrm{Na}_{2} \mathrm{O} \cdot \mathrm{X} \cdot \mathrm{SiO}_{2}\right)\right] \leftrightarrow} \\
& {\left[\left(\text { Argila. }^{+} \mathrm{Na}^{+}\right)^{-}+\downarrow\left(\mathrm{CaO} \cdot \mathrm{X} \cdot \mathrm{SiO}_{2}\right)\right]+\left[\mathrm{Ca}^{2+}\right]}
\end{aligned}
$$

Segundo Tunç ${ }^{[17]}$, os defloculantes orgânicos, polímeros iônico ou não iônico, interagem com a superfície da partícula da argila de diferentes modos. Os polímeros não iônicos promovem a estabilização estérica, que é a consequência da interação física das cadeias poliméricas ${ }^{[8,17,18]}$. Já os polímeros iônicos, como os poliacrilatos, atuam através do mecanismo eletrostérico, uma combinação do mecanismo eletrostático e estérico ${ }^{[8,10,17,19]}$.

A eficiência dos defloculantes pode ser avaliada através das curvas de defloculação, que objetivam determinar a 
quantidade de defloculante necessária para diminuir a viscosidade da suspensão ${ }^{[6]}$. Normalmente os resultados dessas curvas de defloculação são expressados em massa de defloculante consumido por conteúdo de sólidos ou viscosidade da suspensão. Normalmente quando se faz uma curva de defloculação poucas informações sobre as propriedades das argilas são avaliadas, dificultando a comparação entre resultados. Por vezes, no dia a dia de fábrica, isso pode gerar dúvidas quanto a eficiência ou não de um determinado produto ou mesmo quanto a viabilidade de uso de alguma argila com potencial de emprego na formulação.

Nas suspensões argilosas o comportamento reológico e o consumo de defloculante dependerá das propriedades intrínsecas de cada argila: composição mineralógica, tamanho de partícula, capacidade de troca catiônica, área de superfície específica, teor de matéria orgânica e $\mathrm{pH}$. Quando duas ou mais argilas precisam ser comparadas em termos de consumo de defloculantes ou viscosidade mínima, podem surgir dificuldades em identificar quais propriedades de argila predominam: tipo e quantidade dos argilominerais e tamanho de partícula, por exemplo.

Alguns estudos já demonstraram algumas correlações isoladamente: (1) o consumo de defloculante aumenta em função do teor de argilomineral presente na suspensão ${ }^{[6]}$, (2) o aumento na concentração de cátions bivalentes na suspensão provoca um aumento na viscosidade e na quantidade de defloculante adicionado ao sistema ${ }^{[1]}$, (3) argilas com maior área de superfície específica tendem a apresentar maiores viscosidade ${ }^{[22]}$. Apesar disso é muito difícil, na prática, isolar bem o sistema e saber até que ponto cada uma destas propriedades realmente interfere no consumo de defloculante de uma barbotina. No presente trabalho algumas argilas foram cuidadosamente selecionadas na tentativa de se estudar isoladamente os fatores que mais interferem no consumo de defloculante e na viscosidade. A partir disso tentar identificar características que possam auxiliar os técnicos conhecer melhor uma argila e suas consequências, positivas ou negativas, para o processo de fabricação.

\section{Experimental}

\subsection{Materiais}

As argilas do grupo da caulinta e do grupo da ilita são as de uso mais recorrente neste setor. Para a realização deste trabalho estudou-se a defloculação de argilas do grupo da caulinita e do grupo da ilita. Adotou-se o seguinte critério de escolha das amostras: (1) um caulim beneficiado típico, (2) uma argila caulinítica conhecida como de fácil defloculação (AC-1), (3) uma argila caulinítica de difícil defloculação (AC-2), (4) uma argila ilítica de fácil defloculação, mas que preferencialmente não tivesse montmorilonita na composição (AI-1) e (5) uma argila ilítica de difícil defloculação, mas que preferencialmente não tivesse montmorilonita na composição (AI-2).

$\mathrm{O}$ caulim selecionado é tipicamente empregado na formulação de esmaltes cerâmicos e foi fornecido pela Empresa Eliane Revestimentos Cerâmicos, sendo proveniente da Paraíba. As argilas cauliníticas foram fornecidas pela T-Cota Engenharia e Minerais Industriais, e são provenientes de Campo Alegre, SC. Ambas as argilas ilíticas também foram fornecidos pela T-Cota, provenientes de Picos, PI.

Todas as matérias-primas foram submetidas à secagem a $60^{\circ} \mathrm{C}$ até massa constante e passadas em peneira com abertura de $45 \mu \mathrm{m}$. É importante observar que para estudos de defloculação de argilas não se recomenda secar as amostras em temperatura superior a $60^{\circ} \mathrm{C}$, pois afeta o significativamente as informações de consumo de defloculante e viscosidade.

\subsection{Caracterização das matérias-primas}

A análise química foi realizada via espectrometria de fluorescência de raios X em espectrômetro modelo PW 2400, marca PANalytical. A composição mineralógica das argilas foi confirmada com difração de raios X, em difratômetro Shimadzu, modelo XRD 6000, com potência de $30 \mathrm{kV}$ e corrente de $30 \mathrm{~mA}$. As matérias-primas receberam radiação de $\mathrm{K} \alpha \mathrm{Cu}$ entre 5 a $40^{\circ}$ numa taxa de $1 \%$ min. para as argilas preparadas em suspensão e glicoladas, e de 10 a $80^{\circ}$ numa taxa de $4 \%$ min. para o caulim e as argilas cauliníticas.

A capacidade de troca catiônica foi determinada pelo método de saturação da argila com solução de $\mathrm{BaCl}_{2}$ seguindo-se da determinação da quantidade de cátion fixada na superfície da argila pelo método de absorção atômica.

A distribuição de tamanho de partícula foi realizada com a amostra na forma de suspensão, no aparelho Sedigraph 5000d, no LaRC/DEMA - UFSCar (São Carlos - SP). As amostras para essa análise foram correspondentes ao ponto de máxima de defloculação, defloculadas com silicato de sódio.

Aárea de superfície específica foi determinada segundo o método BET e o percentual de carbono orgânico das matérias-primas foi realizada via titulação de retorno.

Para a medição do $\mathrm{pH}$ das argilas, foi preparada uma suspensão com água deionizada com $50 \%$ de sólidos, e posteriormente medido o $\mathrm{pH}$ com fitas indicadoras de $\mathrm{pH}$. $\mathrm{O}$ potencial zeta foi medido em equipamento Zetasizer Malvern, entre os pH 1 e 12.

\subsection{Curvas de defloculação}

Os defloculantes foram sintetizados em laboratório, com base nos ânions silicato e poliacrilato foram produzidos seus respectivos sais à base de lítio, sódio e potássio. Para os silicatos partiu-se da sílica amorfa em suspensão de água deionizada e para os poliacrilatos partiu-se do ácido poliacrílico. Ao final foram usados os seguintes defloculantes: $1,2 \mathrm{Na}_{2} \mathrm{O} .1 / 2 \mathrm{Li}_{2} \mathrm{O} .3,4 \mathrm{SiO}_{2}, \mathrm{Na}_{2} \mathrm{O} .2 \mathrm{SiO}_{2}$,

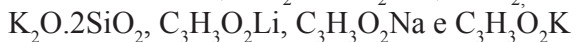

Para cada ponto da curva, o defloculante foi primeiro adicionado à água e adicionado às matérias-primas. As curvas de defloculação foram preparadas com adição de no mínimo cinco diferentes concentrações de íons (cinco pontos). As suspensões de argila foram preparadas com $50 \%(\mathrm{~m} / \mathrm{m})$ de teor de sólidos, com exceção para as suspensões de caulim, que foram preparadas com $63 \%$ 
em peso de sólidos. Esta alteração se fez necessária pois em teores de sólidos inferiores não foi possível uma identificação clara do ponto de trabalho de defloculação devido à baixa viscosidade.

Para se garantir uma boa homogeneidade e interação do defloculante com as argilas foi utilizado um moinho planetário utilizando bolas de alumina durante $10 \mathrm{~min}$ (300 g de sólidos e $500 \mathrm{~g}$ de bolas de alumina). No entanto, para o caulim, por se tratar de uma matéria-prima já beneficiada, a homogeneização foi realizada em agitador mecânico por 3 minutos. As curvas de defloculações foram obtidas a partir da adição de quantidades crescentes de defloculantes. Para cada ponto da curva, foi medido o tempo de escoamento em copo Ford de $100 \mathrm{~mL}$ com abertura de $4 \mathrm{~mm}$ e densidade em picnômetro de $100 \mathrm{~mL}$. Após 7 dias de repouso as suspensões foram redispersadas e medido novamente o tempo de escoamento. Com isso, selecionou-se 3 pontos característicos da curva e mediu-se a viscosidade em viscosímetro rotacional Brookfield com variação da rotação de 0,5 a $100 \mathrm{rpm}$. Os três pontos característicos correspondem a: (1) ponto onde a suspensão apresentou escoamento no copo Ford (início da defloculação); (2) ponto do teor ótimo de defloculante (por vezes chamado ponto ótimo), que usualmente seria aplicado industrialmente; (3) um ponto além do ótimo (maior teor de defloculante que o mínimo). A concentração de defloculante foi calculada em relação à massa seca.

$\mathrm{O}$ consumo específico de cátion na defloculação foi medido através de Espectrofotômetro de Absorção Atômica em Chama ${ }^{23}$. As amostras denominadas "branco" correspondem à mistura defloculante + água, antes da adição da fração argilosa, para fins de referência direta ao sistema após adição da fração argilosa.

A quantidade de cátions monovalentes envolvidos na defloculação do sistema corresponde ao número total de cátions monovalentes "ativos" no sistema, ou seja, a concentração de cátions inicialmente adsorvidos na superfície de argila mais a concentração na solução aquosa, equação $2^{23}$ :

$$
X_{T}=\sum_{i} \frac{X_{i a} \cdot \varphi_{S}+X_{i s} \frac{\left(1-\varphi_{S}\right)}{\varphi_{S}}}{M_{i}}
$$

Onde: $\mathrm{X}_{\mathrm{T}}$ é o consumo de cátions monovalentes no ponto de trabalho $(\mu \mathrm{mol} / \mathrm{g}) ; \mathrm{X}_{\mathrm{ia}}$, a concentração inicial de cátions monovalente adsorvidos ( $\mathrm{ppm})$, determinada a partir do CTC; $\varphi_{\mathrm{s}}$, o conteúdo sólido (fração mássica); $\mathrm{X}_{\mathrm{is}}$, a concentração inicial de cátions monovalentes em solução aquosa (ppm); e MM, a massa molar do cátion monovalente (g/ mol).

\section{Resultados e discussões}

\subsection{Caracterização das matérias-primas}

As tabelas 1, 2 e 3 apresentam os resultados obtidos a partir das análises das amostras de argilas. Posteriormente, construiu-se uma matriz de correlação, listando os fatores de correlação $(\mathrm{R})$ entre as propriedades da argila (Tabela 4). A Tabela 1 apresenta os resultados da análise

Tabela 1. Análise química das argilas

\begin{tabular}{cccccc}
\hline \multirow{2}{*}{ Elementos $(\%)$} & \multicolumn{5}{c}{ Argilas } \\
\cline { 2 - 6 } & Caulim & AC-1 & AC-2 & AI- & AI-2 \\
\hline $\mathrm{SiO}_{2}$ & 47,7 & 73.0 & 58,5 & 64,3 & 57,4 \\
$\mathrm{Al}_{2} \mathrm{O}_{3}$ & 37,3 & 17,6 & 26,6 & 19,9 & 25,4 \\
$\mathrm{CaO}$ & 0,07 & 0,1 & 0,07 & 0,09 & 0,08 \\
$\mathrm{Fe}_{2} \mathrm{O}_{3}$ & 0,3 & 1,2 & 1,6 & 2,88 & 3,0 \\
$\mathrm{~K}_{2} \mathrm{O}$ & 0,6 & 0,8 & 0,7 & 4,7 & 3,6 \\
$\mathrm{MgO}_{\mathrm{MnO}}$ & 0,1 & 0,6 & 0,5 & 1,3 & 1,4 \\
$\mathrm{Na}_{2} \mathrm{O}$ & 0,01 & $<0,01$ & 0,01 & 0,01 & 0,01 \\
$\mathrm{P}_{2} \mathrm{O}_{5}$ & 0,4 & 0,05 & 0,03 & 0,11 & 0,1 \\
$\mathrm{TiO}_{2}$ & 0,08 & 0,02 & 0,05 & 0,3 & 0,2 \\
\hline $\mathrm{PF}$ & 0,01 & 0,67 & 2,21 & 1,02 & 0,87 \\
\hline
\end{tabular}

Tabela 2. Composição de fases mineralógicas das argilas cauliníticas.

\begin{tabular}{lccccc}
\hline \multirow{2}{*}{ Fases mineralógicas (\%) } & \multicolumn{5}{c}{ Argilas } \\
\cline { 2 - 6 } & Caulim & AC-1 & AC-2 & AI-1 & AI-2 \\
\hline Caulinita & 90 & 38 & 61 & 17 & 38 \\
Ilita/Muscovita & 5 & 9 & 10 & 53 & 36 \\
Quartzo & 3 & 51 & 25 & 32 & 20 \\
Ortoclásio & - & - & - & 3 & 1 \\
Acessórios & 2 & 2 & 4 & 5 & 5 \\
Fração argilosa & 95 & 47 & 71 & 70 & 74 \\
\hline
\end{tabular}


Tabela 3. Resumo dos resultados da caracterização das matérias-primas

\begin{tabular}{lccccc}
\hline \multirow{2}{*}{ Caracterizações } & \multicolumn{5}{c}{ Argilas } \\
\cline { 2 - 6 } & Caulim & AC-1 & AC-2 & I-1 & I-2 \\
\hline Fase predominante & $\mathrm{K}(1)$ & $\mathrm{K}(1)$ & $\mathrm{K}(1)$ & $\mathrm{I} / \mathrm{M}(2)$ & $\mathrm{I} / \mathrm{M}(2)$ \\
$\mathrm{CTC}(\mathrm{meq} / 100 \mathrm{~g})$ & 3,2 & 2,9 & 3,7 & 10,9 & 13,1 \\
Fração Na $+\mathrm{K}^{+}$ & 0,53 & 0,45 & 0,49 & 0,34 & 0,30 \\
$\mathrm{BET}\left(\mathrm{m}^{2} / \mathrm{g}\right)$ & 25 & 38 & 77 & 49 & 73 \\
Fração $<0,2 \mu \mathrm{m}(\mathrm{x} 100)$ & 2,4 & 14 & 37 & 25 & 26 \\
Fração $<2 \mu \mathrm{m}(\mathrm{x} 100)$ & 35 & 60 & 75 & 60 & 90 \\
$\mathrm{D}_{50}(\mu \mathrm{m})$ & 4,6 & 2,2 & 0,58 & 2 & 0,55 \\
Fração argilosa & 0,95 & 0,47 & 0,71 & 0,64 & 0,75 \\
Carbono orgânico & 0,11 & 0,13 & 0,32 & 0,13 & 0,14 \\
$\mathrm{pH}^{\mathrm{n}}($ natural $)$ & 6 & 5 & 5 & 6 & 6 \\
$\mathrm{pH}^{\mathrm{d}}($ defloculado $)$ & 7 & 7 & 7 & 6 & 7 \\
potencial zeta no $\mathrm{pH}^{\mathrm{d}}(\mathrm{mv})$ & -24 & -27 & -29 & -26 & -18 \\
\hline
\end{tabular}

*Legenda: $\mathrm{K}$ = Caulinita e I/M = Ilita/muscovita

Tabela 4. Matriz de correlação entre propriedades das argilas.

\begin{tabular}{lcccccccc}
\hline & Fase & CTC & BET & $\begin{array}{c}\text { Fração } \\
<\mathbf{0 , 2} \boldsymbol{\mu m}\end{array}$ & $\begin{array}{c}\text { Fração } \\
<\mathbf{2} \boldsymbol{\mu} \mathbf{m}\end{array}$ & $\begin{array}{c}\text { Fração } \\
\text { argilosa }\end{array}$ & (CO) & (PZ) \\
\hline CTC & 0,99 & 1 & & & & & & \\
BET & 0,35 & 0,45 & 1,0 & & & & & \\
Fração $<0,2 \mu \mathrm{m}$ & 0,32 & 0,36 & 0,93 & 1,0 & & & & \\
Fração $<2 \mu \mathrm{m}$ & 0,49 & 0,59 & 0,92 & 0,80 & 1,0 & & & \\
Fração argilosa (FA) & $-0,05$ & 0,01 & $-0,13$ & $-0,31$ & $-0,33$ & 1,0 & & \\
Carbono orgânico (CO) & $-0,33$ & $-0,27$ & 0,70 & 0,76 & 0,41 & $-0,05$ & 1,0 & \\
Potencial zeta (PZ) & 0,61 & 0,69 & 0,13 & $-0,17$ & 0,35 & 0,37 & $-0,51$ & 1,0 \\
\hline
\end{tabular}

química dos elementos mais representativos e perda ao fogo (PF) de cada argila. Observa-se que que o caulim apresenta uma composição típica da caulinita. As argilas apresentam teores distintos de alumina e sílica, que sugere distintos teores de fase argilomineral. Observa-se a grande quantidade de óxido de potássio das argilas AI-1 e AI-2 em virtude de elas possuírem ilita na sua composição. Na Tabela 2 é apresentada a composição mineralógica das argilas que foram determinadas por procedimento de análise racional.

Os resultados apresentados na Tabela 3 sugerem grande variedade de características entre as argilas selecionadas. A capacidade de troca catiônica variou de 3,2 a 13,1 meq/100g. A área de superfície específica variou de 25 a $77 \mathrm{~m}^{2} / \mathrm{g}$. A fração argilosa variou de 0,47 a 0,95 . $\mathrm{O}$ pH variou de 5 a 6 e o potencial zeta entre -18 e -29 . Diante de tantas informações se faz necessário o uso de uma ferramenta estatística para selecionar qual destas variáveis são mais significativas e representativas para este grupo amostral. Uma matriz de correlação é capaz de indicar variáveis que são mutualmente dependentes entre si e diferenciar daquelas que não são mutualmente dependentes. A tabela 4 é o resultado do cálculo da matriz de correlação. No caso do tipo de fase predominante, que é uma variável qualitativa, adotou-se o número 1 para a fase caulinita e 2 para a fase ilita. A interpretação dos valores da tabela se faz da seguinte forma: quanto mais próximo de 0 for um valor, menor é relação de dependência entre duas variáveis. Quanto mais próximo de 1 mais forte é a correlação em que um aumento no valor de uma variável está associado a um aumento do valor da outra variável. Quanto mais próximo de -1 mais forte é a correlação em que um aumento no valor de uma variável está associado a uma redução no valor de outra variável.

Pode-se observar que a capacidade de troca catiônica (CTC) apresentou correlação de 0,99 com o tipo de fase argilomineral predominante na argila. Quanto maior o teor de ilita, maior o valor de troca catiônica. É muito interessante observar também que o potencial zeta apresentou a segunda maior correlação com a capacidade de troca catiônica. Este resultado faz muito sentido, uma vez que a quantidade de cátions trocáveis em uma argila está diretamente associada a natureza e intensidade da carga elétrica superficial da argila e consequentemente do potencial zeta. Na prática, medir a capacidade de troca catiônica de uma argila carrega também uma informação relativa ao potencial zeta e é um procedimento experimental relativamente mais simples, popular e barato.

Pode-se observar que a área de superfície específica de uma argila apresentou forte correlação com a fração granulométrica $<0,2 \mathrm{e}<2 \mu \mathrm{m}$. Trata-se de um indicador quantitativo simples que pode representar razoavelmente bem uma curva de distribuição de tamanho de partículas. 
Observa-se que a área superficial específica medida pelo método B.E.T também apresentou correlação com o teor de carbono orgânico. A razão para isso reside no fato de quanto maior a área superficial, maior a capacidade o argilomineral adsorver matéria orgânica. Quanto maior o teor de argilomineral em uma argila, também maior tende a ser a área superficial específica. Sabe-se que a fração coloidal está intimamente ligada à fração argilosa, e como o BET está correlacionado com a fração coloidal, seria esperado que houvesse correlação do BET com a fração argilosa. Excluindo o caulim, por se tratar de uma matéria prima beneficiada, o valor da correlação entre BET e fração argilosa passa de $-0,13$ para 0,91 , que está de acordo com o comportamento esperado.

Após a análise da matriz de correlação observa-se que a área superficial específica e a capacidade de troca catiônica são os dois parâmetros mais sensíveis e relevantes para se caracterizar uma argila. Para o grupo de argilas que foi selecionado, BET e CTC apresentaram baixa correlação entre si, 0,35. Dessa forma, também deve ser os parâmetros mais importantes para se analisar o consumo de defloculante, pois se pode identificar claramente qual dos parâmetros mais afeta o consumo de defloculante. O BET representa a condição física e o CTC representa condição química da superfície dos argilominerais.

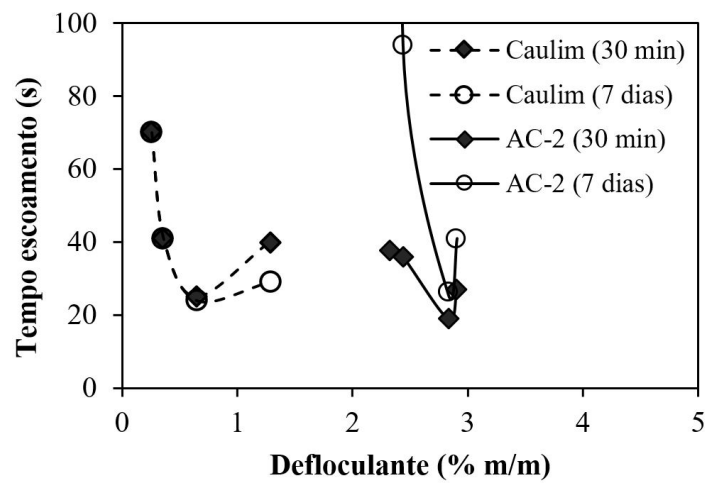

Figura 1. Curva de defloculação para o caulim e argila caulinítica AC-2, após 30 min e 7 dias de repouso.

\subsection{Suspensões}

\subsubsection{Tempo de escoamento:}

A Figura 1 mostra as curvas de defloculação (tempo de escoamento em função do percentual mássico do defloculante) do caulim e da argila AC-2 (menor e maior teor de carbono orgânico, respectivamente), após 30 min e após 7 dias de repouso. No ponto de trabalho, o caulim requer uma quantidade menor de defloculante que $\mathrm{AC}-2$ e o tempo de escoamento é semelhante para ambas suspensões, no entanto a suspensão de caulim apresenta um teor de sólidos de 63\% e o AC-2 50\%. O tempo de repouso não afetou o ponto de trabalho em nenhum dos casos. Por outro lado, após 7 dias o AC-2 apresentou um leve aumento no tempo de escoamento. Na prática o que importa para o processamento de uma barbotina é definir adequadamente o ponto de trabalho. Outros estudos apresentaram resultados semelhantes medindo propriedades reológicas ${ }^{24}$ correlacionando inclusive o efeito do teor de matéria orgânica. Observa-se que a matéria orgânica pode ter algum efeito muito relevante para as regiões mais afastadas do ponto de trabalho. Desse modo, é provável que o teor de matéria orgânica afete a defloculação de uma barbotina para aqueles casos onde se esteja adicionando menos defloculante do que o necessário.

\subsubsection{Consumo de defloculante:}

A concentração de cátions monovalentes no ponto de trabalho $\left(\mathrm{X}_{\mathrm{T}}\right)$ difere consideravelmente entre as diferentes argilas (Tabela 5). As argilas AC-1 e AC-2 requerem uma maior concentração de cátions do que as outras matérias-primas. Para argila AI-1, $\mathrm{X}_{\mathrm{T}}$ é menor em comparação com outras argilas e caulim e argila AI-2 mostram um valor intermediário. O tipo de defloculante não afeta $\mathrm{o} \mathrm{X}_{\mathrm{T}}$.

Uma análise estatística (ANOVA) foi realizada ${ }^{23}$ para os valores de $\mathrm{X}_{\mathrm{T}}$ em função de BET e CTC e verificou-se que ambas variáveis exercem influência nos valores de $\mathrm{X}_{\mathrm{T}}$, porém a contribuição de BET é mais significativa. A equação 3 é a função ajustada para predição do consumo de defloculante ${ }^{23}$.

Tabela 5. Consumo de defloculante e viscosidade no ponto de trabalho para as diferentes argilas

\begin{tabular}{|c|c|c|c|c|c|c|}
\hline & \multicolumn{2}{|c|}{ Caulim } & AC-1 & $\mathrm{AC}-2$ & AI-1 & AI-2 \\
\hline \multicolumn{7}{|c|}{ Consumo de defloculante $(\mu \mathrm{mol} / \mathrm{g})$} \\
\hline Cátion & Silicato & Poliacrilato & Silicato & Silicato & Silicato & Silicato \\
\hline $\mathrm{Li}, \mathrm{Na}$ & 38 & 37 & 115 & 284 & 40 & 96 \\
\hline $\mathrm{Na}$ & 40 & 41 & 284 & 40 & 96 & 40 \\
\hline $\mathrm{K}$ & 44 & 50 & 40 & 96 & 40 & 40 \\
\hline \multicolumn{7}{|c|}{ Viscosidade (mPa·s à 60 rpm) } \\
\hline $\mathrm{Li}, \mathrm{Na}$ & $2 *$ & 2 & 4 & 66 & 47 & 59 \\
\hline $\mathrm{Na}$ & $2 *$ & 2 & 3 & 37 & 14 & 35 \\
\hline $\mathrm{K}$ & $2 *$ & 6 & 4 & 43 & 16 & 22 \\
\hline
\end{tabular}

*Valores normalizados para conteúdo de sólidos de 50 wt.\% de acordo com o modelo de De Noni et al. (2002), para viscosidade em função da fração volumétrica de sólidos. 


$$
\mathrm{X}_{\mathrm{T}}=\mathrm{a}_{3} \cdot \mathrm{BET}-\mathrm{a}_{4} \cdot \mathrm{CTC}
$$

onde: $\mathrm{a}_{3}=(3,0 \pm 0,3) \mathrm{mmol} / \mathrm{m}^{2}$ e $\mathrm{a}_{4}=(1,2 \pm 0,2) \mathrm{mmol} / \mathrm{mEqg}$ são constantes empíricas. Quando ambos os membros da equação 3 (BET e CTC) são divididos por BET, tem-se a equação 4.

$$
\mathrm{X}_{\mathrm{m}^{2}}=\mathrm{a}_{3}-\mathrm{a}_{4} \cdot \mathrm{CTC}^{*}
$$

onde: $\mathrm{X}_{\mathrm{m}^{2}}$ é a concentração específica de cátions monovalentes no ponto de trabalho $\left(\mathrm{mmol} / \mathrm{m}^{2}\right)$, chamado de consumo específico de defloculante; $\mathrm{CTC}^{*}$ é a capacidade de troca catiônica específica da argila $\mathrm{mEqg} / \mathrm{m}^{2}$.

Em geral a Equação 4 representa o consumo específico de defloculante (consumo de cátions monovalentes) em função das principais propriedades da argila. A análise estatística mostrou que essa equação é válida para todos os tipos de argila (caulinita ou ilita). O maior teor de matéria orgânica da argila AC-2 não afetou significativamente esse resultado. Embora empírico, este modelo sugere um ponto de partida para estimar o consumo de defloculante para suspensões argilosas concentradas em água deionizada.

Na Figura 2, é mostrado o consumo específico de defloculante $\left(\mathrm{X}_{\mathrm{m}^{2}}\right)$ versus BET. É observado que o aumento da área de superfície das argilas provoca aumento do consumo de defloculante. Os pontos do gráfico estão diferenciados por tipo de argila. Seguindo a tendência, observa-se que para um mesmo BET, as caulinitas tendem a consumir maior teor de defloculante em relação às argilas ilíticas.

$\mathrm{O}$ coeficiente de correlação, $\mathrm{R}^{2}$, é uma medida de ajustamento de um modelo estatístico linear em relação aos valores observados. $\mathrm{O}$ valor de $\mathrm{R}^{2}$ varia entre 0 e 1 , indicando, em percentagem, o quanto o modelo consegue explicar os valores observados. Quanto maior o $\mathrm{R}^{2}$, mais explicativo, mais válido é o modelo e melhor ele se ajusta à amostra. Ainda para a Figura 2, foi identificada uma baixa correlação, $\mathrm{R}^{2}=0,08$, quando as fases não são distinguidas.

$\mathrm{Na}$ Figura 3 (consumo específico de defloculante em função da capacidade de troca catiônica) é possível verificar a tendência de redução do consumo de defloculante com o aumento da CTC, mesmo com uma baixa correlação $\left(\mathrm{R}^{2}=0,5\right)$, e oposta àquela do BET. Observando dentro de um mesmo grupo (caulinitas ou ilitas) não é possível estabelecer uma relação consistente.

Assim como o consumo de defloculante foi expresso em termos de número de mols por área superfície específica $\left(\mu \mathrm{mol} / \mathrm{m}^{2}\right)$, a capacidade de troca catiônica também poderia ser expressa da mesma forma $\left(\mathrm{meq} / \mathrm{m}^{2}\right.$ ou eq. $\left./ \mathrm{m}^{2}\right)$. Portando, o consumo específico de defloculante estaria sendo avaliado levando-se em consideração simultaneamente CTC e BET. O resultado da aplicação da equação 4 está representado na Figura 4 (consumo específico de defloculante $\mathrm{x}$ capacidade de troca catiônica específica).

É observado uma excelente correlação entre ambas as variáveis, demonstrando que o consumo de defloculante é menor à medida que aumenta a capacidade de troca catiônica da argila. Esta correlação foi apurada sem fazer qualquer distinção entre o tipo de argilomineral predominante no sistema (caulinita ou ilita). O teor de matéria orgânica, bastante elevado para a argila $\mathrm{AC}-2$ não representou interferência nesta correlação. Essa argila foi a que apresentou o mais baixo índice de $\mathrm{CTC} / \mathrm{m}^{2}$.

$\mathrm{Na}$ literatura, o consumo específico é tipicamente expresso pelo percentual mássico dos sólidos ou em termos de área de superfície ${ }^{5}$. Quando se considera o consumo específico de defloculantes em suspensões argilosas, os seguintes aspectos podem ser delineados: (1) os

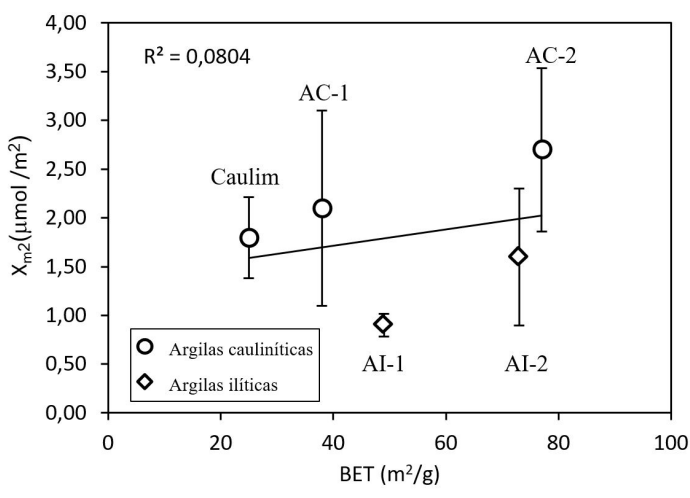

Figura 2. Consumo específico de defloculante $\left(\mu \mathrm{mol} / \mathrm{m}^{2}\right.$ argila $)$ $x$ BET

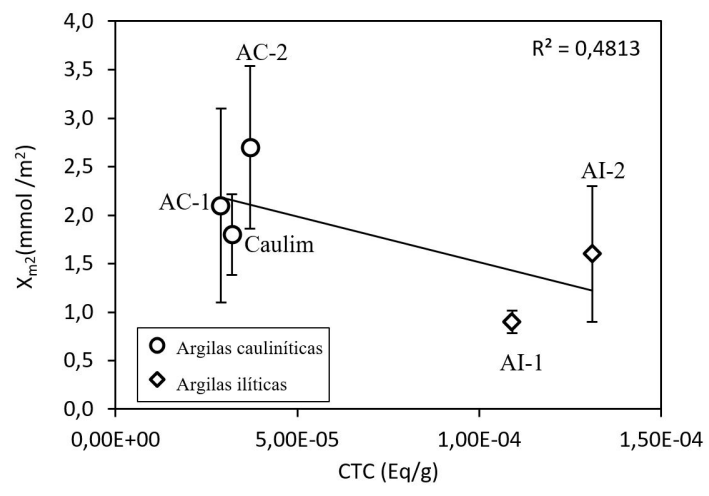

Figura 3. Consumo específico de defloculante $\left(\mu \mathrm{mol} / \mathrm{m}^{2}\right.$ argila $)$ x CTC

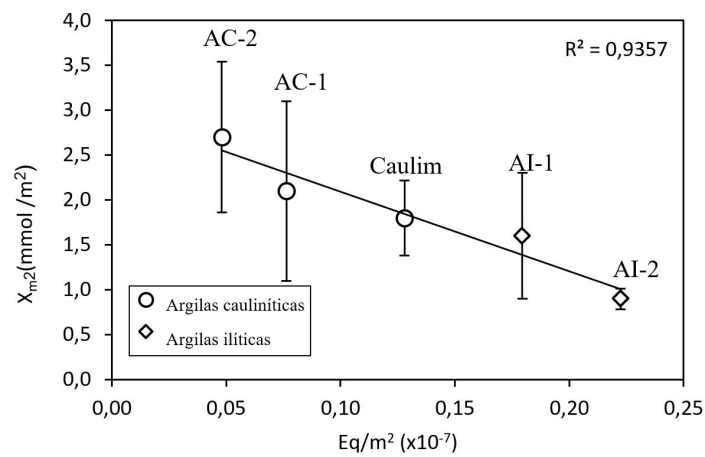

Figura 4. Consumo específico de defloculante, $\mathrm{X}_{\mathrm{m}} 2\left(\mu \mathrm{mol} / \mathrm{m}^{2}\right.$ argila), x capacidade de troca catiônica específica $\mathrm{CTC}^{*}$ ou $\left(\mathrm{CTC} / \mathrm{m}^{2}\right)$. 
argilominerais têm uma área superficial específica maior do que outros minerais não argilosos típicos presentes no sistema, exemplo: quartzo; (2) diferentes argilominerais (por exemplo, caulinita e ilita) têm normalmente diferentes áreas superficiais específicas; (3) a área superficial específica está intimamente relacionada com a distribuição do tamanho de partícula; e (4) o consumo específico (proposto na equação 4) é uma propriedade característica simples, fácil de medir, que pode ser correlacionada com a composição mineralógica e a distribuição granulométrica das suspensões.

\subsubsection{Viscosidade:}

Analisando as argilas por grupos (Tabela 5), nota-se que as argilas AC-2 e I-2 apresentaram viscosidades mais elevadas, e também consumiram maior teor de defloculante. A argila AC-1 apresentou menor viscosidade, entre 3 e 4 cP. As viscosidades da argila AI-1 e do caulim, que consumiram menos defloculantes, foram intermediárias em relação às demais argilas. Avaliando os defloculantes, de modo geral, as argilas defloculadas com silicato de sódio e de potássio apresentaram viscosidades semelhantes e menores. As defloculações com silicato de lítio-sódio apresentaram viscosidades mais elevadas.

Dentre as propriedades, a relação mais nítida com a viscosidade é verificada com o tamanho de partícula. A fração abaixo de $0,2 \mu \mathrm{m}$ é tão importante quanto a fração abaixo de $2 \mu \mathrm{m}$. A argila AI-1 em comparação com a AI-2 possui menor viscosidade, menor volume de partículas abaixo de $0,2 \mu \mathrm{m}$, porém maior volume

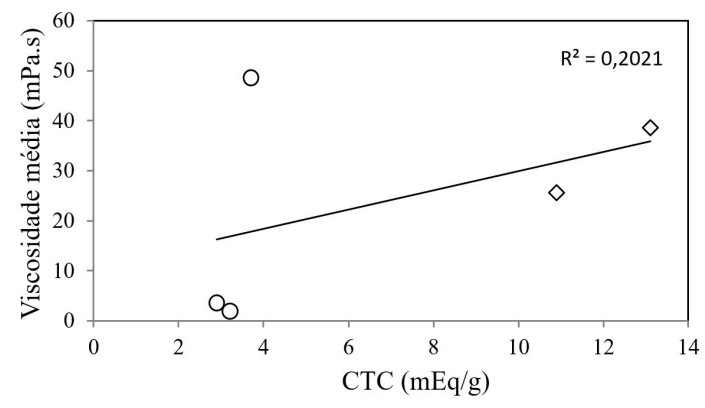

Figura 5. Viscosidade média (mPa.s) x capacidade de troca catiônica $(\mathrm{mEq} / \mathrm{g}) .(\mathrm{O}=$ argilas cauliníticas; $\diamond=$ argilas líticas $)$

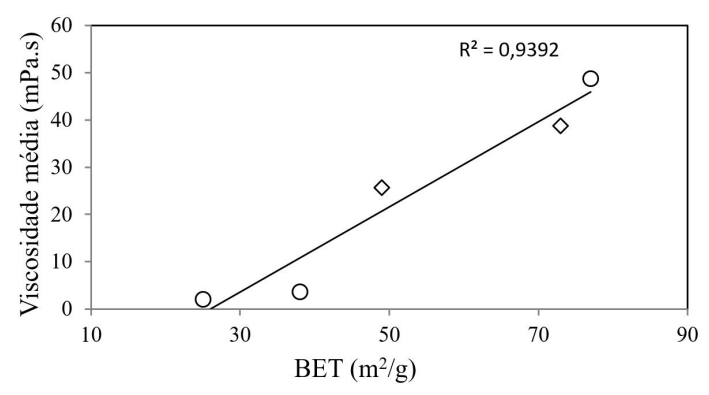

Figura 6. Viscosidade média (mPa.s) x área de superfície específica $\left(\mathrm{m}^{2} / \mathrm{g}\right)$. $(\mathrm{O}=$ argilas cauliníticas; $\diamond=$ argilas líticas $)$ abaixo de $2 \mu \mathrm{m}$. A AC-2 em comparação com a AI-2, possui maior viscosidade, maior fração abaixo de $0,2 \mu \mathrm{m}$ e menor fração abaixo de $2 \mu \mathrm{m}$.

Conforme visto na Tabela 5, tanto a fração $<0,2 \mu \mathrm{m}$ quanto a $<2 \mu \mathrm{m}$ estão correlacionadas com o BET e não com a CTC. Assim, seria esperado que a viscosidade também pudesse apresentar este comportamento. De fato, observando a Figura 5 é visto que a viscosidade não é dependente da capacidade de troca catiônica e que o coeficiente de correlação apresentou-se muito baixo $(0,2)$.

No entanto, observando a Figura 6, o comportamento da viscosidade média é dependente do BET de modo que as argilas com maior área de superfície específica apresentam maiores valores de viscosidades médias (sem distinção dos grupos e argilas) e nota-se um alto valor de $\mathrm{R}^{2}$.

A análise estatística (ANOVA) realizada ${ }^{23}$ levando em consideração a viscosidade em função de BET e CTC e mostrou que a viscosidade é afetada pelo BET mas não pela CTC, corroborando os comportamentos verificados na Figuras 5 e 6 . Estes resultados indicam consistentemente que uma vez que uma argila é defloculada, a viscosidade depende de suas propriedades físicas. Neste caso, o BET pode representar distribuições de tamanho de partícula e suas características relacionadas.

Ainda com base na análise estatística ${ }^{23}$, tem-se a Equação 5, podendo ser utilizada como predição da viscosidade aparente a $60 \mathrm{rpm}$ (viscosímetro Brookfield) e $50 \%$ de sólidos.

$$
\eta=a_{1}+a_{2} \cdot S a
$$

onde: $\eta$ é viscosidade aparente ( $\mathrm{mPa} \mathrm{s})$; Sa é BET $\left(\mathrm{m}^{2} / \mathrm{g}\right)$; $\mathrm{a}_{1}=21 \pm 7 \mathrm{mPa} \cdot \mathrm{s}$ e $\mathrm{a}_{2}=0,860,16\left(\mathrm{~g} / \mathrm{m}^{2}\right)(\mathrm{mPa} \cdot \mathrm{s})$ são constantes empíricas.

\section{Conclusão}

Este estudo mostrou que as matérias-primas selecionadas apresentam propriedades variáveis que permitem identificar semelhanças e diferenças no comportamento reológico e no consumo de defloculante. A CTC e o BET são os dois parâmetros mais importantes relacionados ao consumo do defloculante, representando aspectos físicos e químicos da superfície dos argilominerais, respectivamente.

A viscosidade das suspensões do consumo de defloculante, porém no ponto de trabalho não houve correlação entre o consumo de defloculantes e a viscosidade, no entanto, a viscosidade está diretamente relacionada à área superficial específica.

O consumo de defloculante está associado à relação CTC/BET, que foi definida como capacidade de troca catiônica específica. O consumo de defloculante é maior para aquelas argilas com uma baixa relação CTC/BET. O modelo proposto poderia ser usado como uma primeira estimativa do consumo mínimo de cátions em suspensões argilosas com alta concentração de sólidos.

Na prática, ao caracterizar uma argila ou uma composição de massa através da técnica de capacidade de troca catiônica e área superficial específica, é possível ter uma ideia mais 
ou menos clara, do consumo de defloculante que uma suspensão terá, assim como sua viscosidade mínima. Quanto maior a relação de CTC/BET menor consumo de defloculante. Quanto maior a área superficial específica, maior a viscosidade no ponto de trabalho.

\section{Agradecimentos}

Os autores agradecem ao Instituto Maximiliano Gaidzinski, Universidade do Extremo Sul de Catarinense e a Universidade Federal de Santa Catarina, pela infra-estrutura, e a CAPES - Coordenação de Aperfeiçoamento de Pessoal de Nível Superior, pelo apoio financeiro através da concessão de bolsa de estudos.

\section{Referências}

[1] Andreola, F., Castellini, E., Ferreira, J. M.F, Romagnoli, M. Effect of sodium hexametaphosphate and ageing on the rheological behavior of kaolin dispersions. Applied Clay Science, 2006, 31, 56-64.

[2] De Noni, A., Garcia, D.H., Hotza, D. A modified for the viscosity of ceramic suspensions. Ceramic International, 2002, 28, 731-735.

[3] Zupancic, A., Lapasin, R., Kristoffersson, A. Influence of particle concentration on rheological properties of aqueous $-\mathrm{Al}_{2} \mathrm{O}_{3}$ suspensions. Journal of the European Ceramic Society. 1997, 18, 467-477.

[4] Valdivieso, F., Goeuriot, P., Thevenot, F. Dispersion of three ceramic powders in a slurry. The $\mathrm{Al}_{2} \mathrm{O}_{3}-\mathrm{AlN}-\mathrm{SiC}$ mixture. Journal of the European Ceramic Society. 1997, 17, 377382.

[5] Pandolfelli, V. C., Oliveira, R., Studart, A. R., Pileggi, R. G., Dispersão e Empacotamento de Partículas, Fazendo Arte Editorial, S. Paulo, 2000, p. 29.

[6] Gomes, C.M., Reis, J.P., Luiz, J. F., Oliveira, A. P. N., Hotza, D. Deflocculation of triaxial ceramic suspensions using a mixture design approach. Cerâmica, 2005, 51, 336-342.

[7] Marco, P., Labanda, J., Llorens, J. The effect of polyelectrolyte chemical compositions on the rheological behavior of kaolin suspensions. Powder Technology, 2004, 148, 43-47.

[8] Traiphol, N.; Suntako, R.; Chanthornthip, K. Roles of polymeric dispersant charge density on lead zirconate titanate aqueous processing . Ceramics International, 2010, 36, 2147-2153.

[9] Dinger, D. R., Rheology for ceramists, Kearney: Morris Publishing, 2002.

[10] Romagnoli, M., Andreola, F. Mixture of deflocculants: A systematic approach. Journal of the European Ceramic Society, 2007, 27, 1871-1874.
[11] Penner, D., Lagaly, G., influence of anions on the rheological properties of clay mineral dispersions. Applied Clay Science, 2001, 19, 131-142.

[12]Delavi, D. G. G., Defloculação de suspensões aquosas de argilas e sua correlação com caracterizações químicas e de superfícies. 2011. 126 p. Dissertação (Mestrado em Ciência e Engenharia de Materiais) Universidade Federal de Santa Catarina, Florianópolis, 2011.

[13] Amaros, J. L., Beltrán, V., Sanz, V., Jarque, J. C. Electrokinetic and rheological properties of highly concentred kaolin dispersions: influence of particle volume fraction and dispersant concentration. Applied Clay Science, 2010, 49, 33-43.

[14] Andreola, F., Castellini, E., Manfredini, T., Romagnoli, M. The role of sodium hexametaphosphate in the dissolution process of kaolinite and kaolin. Journal of the European Ceramic Society, 2004, 24, 2113-2124.

[15] Manfredini, T., Pellacani, G.C., Pozzi, P., Corradi, A. B. Monomoric andoligmeric phosphates as deflocculants of concentrated aqueous clays suspensions. Applied Clay Science, 1990, 5, 193-201.

[16]Lagaly, G., Principles of flow of kaolin and bentonite dispersions. Applied Clay Science, 1989, 4, 105-123.

[17] Tunç, S., Duman, O. The effect of different molecular weight of poly(ethylene glycol) on the electrokinetic and rheological properties of Na-bentonite suspensions. Colloids and surfaces, 2008, 317, 93-99.

[18] Tomasik, P., Schilling, C. H., Jankowiak, R., Kim, J. C. The role of organic dispersants in aqueous alumina suspensions. Journal of the European Ceramic Society, 2003, 23, 913-919.

[19] Alemdar, A., Öztekin, N., Erim, F.B., Ece, Ö, I., Güngör, N. Effect of polyethyeinemine adsorption on the Rheology of bentonite suspensions, Bull Mater Sci.,2005, 28, 287-291.

[20] Santos, P. S. Ciência e tecnologia de argilas. 2 ed. v. 3 São Paulo: E. Blücher, 1992.

[21]Bergaya, F. B.; Theng, K.G.; Lagaly, G. Handbook of Clay Science. v.1, Elsevier Science, 2006.

[22] Ortega, F.S. et al, Aspectos da Reologia e da Estabilidade de Suspensões Cerâmicas: Parte II, Cerâmica, v. 43, p. $238-243,1997$.

[23] Delavi, D.G.G., De Noni, A., Hotza, D. Deflocculant consumption of clay suspensions as a function of specific surface area and cation exchange capacity. Clay Minerals, 2013 v. 48, p. 473-480.

[24] Lemos A.F. \& Ferreira J.M.F. Influence of Organic Matter on Rheology and Ageing Behaviors of Ball Clay Slurries. 3th National Meeting of the Portuguese Society of Rheology, Mirandela, 2001. p. 110-120 